\title{
Espécies potenciais para recuperação de áreas degradadas a partir de levantamento florístico realizado no Planalto Catarinense
}

\author{
Potential species for recovery of degraded areas from floristic survey conducted in the \\ Planalto Catarinense
}

\author{
Daiany Augusta Paes Martins*, Júlia Maria Erdmann, Amanda Miguel Lemos, Felipe Fornara Walter, \\ Ana Carla Lanzarini, Maria Raquel Kanieski
}

Universidade do Estado de Santa Catarina, Lages, SC. Brasil. *Autor para correspondência: dapmflorestal@gmail.com

\begin{abstract}
RESUMO
Este estudo teve como objetivos avaliar a composição florística e a estrutura fitossociológica de uma área de preservação permanente em Floresta Ombrófila Mista Aluvial no Planalto Catarinense e indicar espécies arbóreas potenciais para a restauração de áreas em locais com características semelhantes. A área de estudo localiza-se no município de Otacílio Costa, SC, nas margens do rio Canoas. Para o levantamento florístico foram alocadas 24 parcelas de $10 \mathrm{~m} \times 10 \mathrm{~m}$, nas quais todos os indivíduos com $\mathrm{CAP} \geq 5 \mathrm{~cm}$ foram medidos, identificados e quantificados seus descritores fitossociológicos. A diversidade foi avaliada utilizando-se o índice diversidade de Shannon-Wiener ( $\mathrm{H}^{\prime}$ ) e equabilidade de Pielou (J). Foram identificados 547 indivíduos, pertencentes a 22 famílias, distribuídos em 34 gêneros. Myrtaceae e Asteraceae foram às famílias de maior riqueza. Quanto à guilda de regeneração a maioria das espécies foi classificada em pioneira (45\%), secundária inicial e secundária tardia (26\% cada). Em relação à síndrome de dispersão as espécies foram classificadas em zoocóricas (71\%), anemocóricas (26\%) e autocóricas (3\%). O índice de diversidade de Shannon-Wiener foi de 2,9 e o índice de equabilidade foi de 0,78 . As espécies que apresentaram os maiores valores de importância, com potencial para restauração florestal, foram Mimosa scabrella, Schinus terebinthifolius e Gymnanthes klotzschiana.
\end{abstract}

PALAVRAS-CHAVE: descritores fitossociológicos, área de preservação permanente, restauração florestal.

\begin{abstract}
The objective of this study was to evaluate the floristic composition and phytosociological structure of a permanent preservation area in Alluvial Mixed Ombrophylous Forest in the Planalto Catarinense and to indicate potential tree species for the restoration of areas in similar sites. The study area is located in the municipality of Otacílio Costa, SC, on the banks of the Canoas River. For the floristic survey 24 plots of $10 \mathrm{~m} \times 10 \mathrm{~m}$ were allocated in which all individuals with CAP $\geq 5 \mathrm{~cm}$ were measured, identified and quantified their phytosociological descriptors. The diversity was evaluate using the Shannon-Wiener diversity index $\left(\mathrm{H}^{\prime}\right)$ and Pielou equability index $(\mathrm{J})$. A total of 547 individuals belonging to 22 families were identified, distributed in 34 genera. Myrtaceae and Asteraceae as richer families. As for the regeneration guild, most species were classified as pioneers (45\%), initial secondary and late secondary (26\% each). Regarding the dispersion syndrome, the species were classified as zoochorous $(71 \%)$, anemochorous $(26 \%)$ and autochorous (3\%). The Shannon-Wiener diversity index was 2.9 and the equability index was 0.78 . The species with the highest values of importance, with potential for forest restoration, were Mimosa scabrella, Schinus terebinthifolius and Gymnanthes klotzschiana.
\end{abstract}

KEYWORDS: phytosociological descriptors, permanent preservation area, forest restoration.

\section{INTRODUÇÃO}

O Estado de Santa Catarina está inserido no Bioma Mata Atlântica, o qual é composto pelas formações de Floresta Ombrófila Mista, Floresta Estacional Decidual e Floresta Ombrófila Densa (IBGE 2012). O Planalto Catarinense está contido na tipologia Floresta Ombrófila Mista, conhecida também como Mata das Araucárias, que atualmente possui aproximadamente $2 \%$ da composição original (RODE et al. 2011). Isso ocorreu devido à grande exploração para ocupação da região Sul do Brasil no primeiro ciclo econômico, causada pelo intenso processo de extrativismo e substituição da cobertura vegetal original por 
atividades agrícolas, pecuárias e de silvicultura, além do crescimento das zonas urbanas (FUNDAÇÃO SOS MATA ATLÂNTICA \& INPE 1998). Essa tipologia merece destaque devido à relevante biodiversidade de fauna e flora, importância socioeconômica (MARQUESINI 1995, GUERRA et al. 2002) e beleza cênica peculiar no Planalto Meridional Catarinense (ALARCON et al. 2011).

A ocupação urbana, agrícola e o uso silvicultural no Planalto Catarinense fizeram com que a fragmentação de vegetação nativa atingisse áreas ribeirinhas e de preservação permanente (TRES \& REIS 2007). Dessa forma, para atender o Código Florestal, essas áreas devem ser recuperadas para que voltem a desempenhar seu papel ecológico, já que elas têm a função ambiental de preservar os recursos hídricos, a paisagem, a estabilidade geológica e a biodiversidade, facilitar o fluxo gênico de fauna e flora, proteger o solo e assegurar o bem-estar das populações humanas (BRASIL 2012).

$\mathrm{Na}$ recuperação e restauração de ambientes degradados e antropizados, o conhecimento da vegetação é essencial para recompor determinada área degradada o mais próximo possível da original. Dessa forma, estudos florísticos e fitossociológicos de vegetação remanescente, próxima as áreas de interesse ou até na própria área são desenvolvidos para que esse conhecimento seja possível (ALMEIDA 2016). A densidade, frequência, dominância e regeneração natural indicarão a escolha adequada da vegetação que irá compor a comunidade vegetal a iniciar o processo de sucessão da área degradada (NERI et al. 2011). Além disso, o conhecimento sobre alguns aspectos ecológicos como as síndromes de dispersão de propágulos e a distribuição espacial dos indivíduos (NEGRINI et al. 2012) são fundamentais para subsidiar estratégias de conservação.

Dessa forma, este estudo teve como objetivos avaliar a composição florística e estrutura fitossociológica de uma área de preservação permanente em Floresta Ombrófila Mista Aluvial no Planalto Catarinense e indicar espécies arbóreas potenciais para restauração de áreas em locais com características semelhantes.

\section{MATERIAL E MÉTODOS}

\section{Área de estudo}

O estudo foi realizado em um trecho de uma área de preservação permanente (APP) localizado no Município de Otacílio Costa, SC, nas margens do rio Canoas. De acordo com a classificação climática de Köppen, o clima é do tipo Cfb, ou seja, clima temperado constantemente úmido, com verões frescos, não apresentando estação seca definida, com temperatura média anual em torno de $17 \stackrel{\circ}{\circ}$ (ALVARES et al. 2014). A precipitação pluviométrica total anual pode variar de $1.360 \mathrm{~mm}$ a $1.600 \mathrm{~mm}$ (EPAGRI 2002), com geadas frequentes.

O solo é classificado como Cambissolo Húmico Alumínico, considerado como solo pouco profundo ou raso, com cores de bruno escuro a bruno avermelhado, argiloso e com horizonte B incipiente (EMBRAPA 2013) e apresentam baixa fertilidade e alta pedregosidade.

A vegetação florestal predominante pertence à Floresta Ombrófila Mista, Mata de Araucária ou Floresta de Pinheiro-brasileiro. A área de estudo é constituída de fragmentos de diferentes estágios sucessionais, resultantes do histórico de perturbação ocorrido no passado, como a abertura de estradas para extração de cascalho e reflorestamento de espécies exóticas, principalmente do gênero Pinus.

\section{Amostragem da vegetação}

Para a amostragem da vegetação foram alocados quatro transectos distanciados $30 \mathrm{~m}$ entre si. Cada transecto foi composto de seis parcelas de $10 \mathrm{~m} \times 10 \mathrm{~m}\left(100 \mathrm{~m}^{2}\right)$, distribuídas sistematicamente, distanciadas $5 \mathrm{~m}$ uma da outra, totalizando 24 parcelas em $2.400 \mathrm{~m}^{2}$ de área amostral. Em cada parcela, todos os indivíduos arbóreos que apresentaram CAP (circunferência à altura do peito, medida a 1,30 m do solo) igual ou superior a $5 \mathrm{~cm}$ foram identificados e mensurados.

\section{Análise dos dados}

Para a identificação, em nível de família, gênero e espécie, juntamente com a grafia dos nomes científicos, foi consultado o sistema Angiosperm Phylogeny Group III (APG 2009) e os bancos de dados eletrônicos da Lista de Espécies da Flora do Brasil (LFB 2016).

As espécies encontradas foram classificadas quanto à guilda de regeneração em pioneiras, secundárias iniciais e secundárias tardias (GANDOLFI et al. 1995) e a síndrome de dispersão segundo a metodologia de VAN DER PIJL (1982).

Para analisar a estrutura horizontal foram calculados os parâmetros fitossociológicos: densidade relativa, frequência relativa, dominância relativa e índice de valor de importância, de acordo com MARTINS (1993). Na apresentação dos resultados, o valor de importância foi dividido por três, como sugerido por HOLDRIDGE et al. (1971), para facilitar sua interpretação, de maneira que o valor possa representar uma 
porcentagem.

A avaliação de diversidade da composição florística foi feita pelo índice de Shannon-Wiener (H') e equabilidade de Pielou $(\mathrm{J})$. Todas as análises foram realizadas no programa estatístico $\mathrm{R}$ e por meio de planilha eletrônica.

A partir das características das espécies encontradas e seus descritores fitossociológicos foram definidas àquelas com potencial para a restauração de áreas.

\section{RESULTADOS E DISCUSSÃO}

$\mathrm{Na}$ composição florística do rio Canoas foram mensurados 547 indivíduos, pertencentes a 42 espécies, distribuídos em 22 famílias e 34 gêneros (Tabela 1). As famílias de maior riqueza foram Myrtaceae (nove) e Asteraceae (quatro), seguidas pelas famílias Anacardiaceae, Euphorbiaceae, Fabaceae e Sapindaceae, com duas cada.

Tabela 1. Espécies amostradas em área de preservação permanente do rio Canoas no município de Otacílio Costa, SC, com seus respectivos parâmetros fitossociológicos.

Table 1. Species sampled in the permanent preservation area of Canoas river in the municipality of Otacilio Costa, SC, with their respective phytosociological parameters.

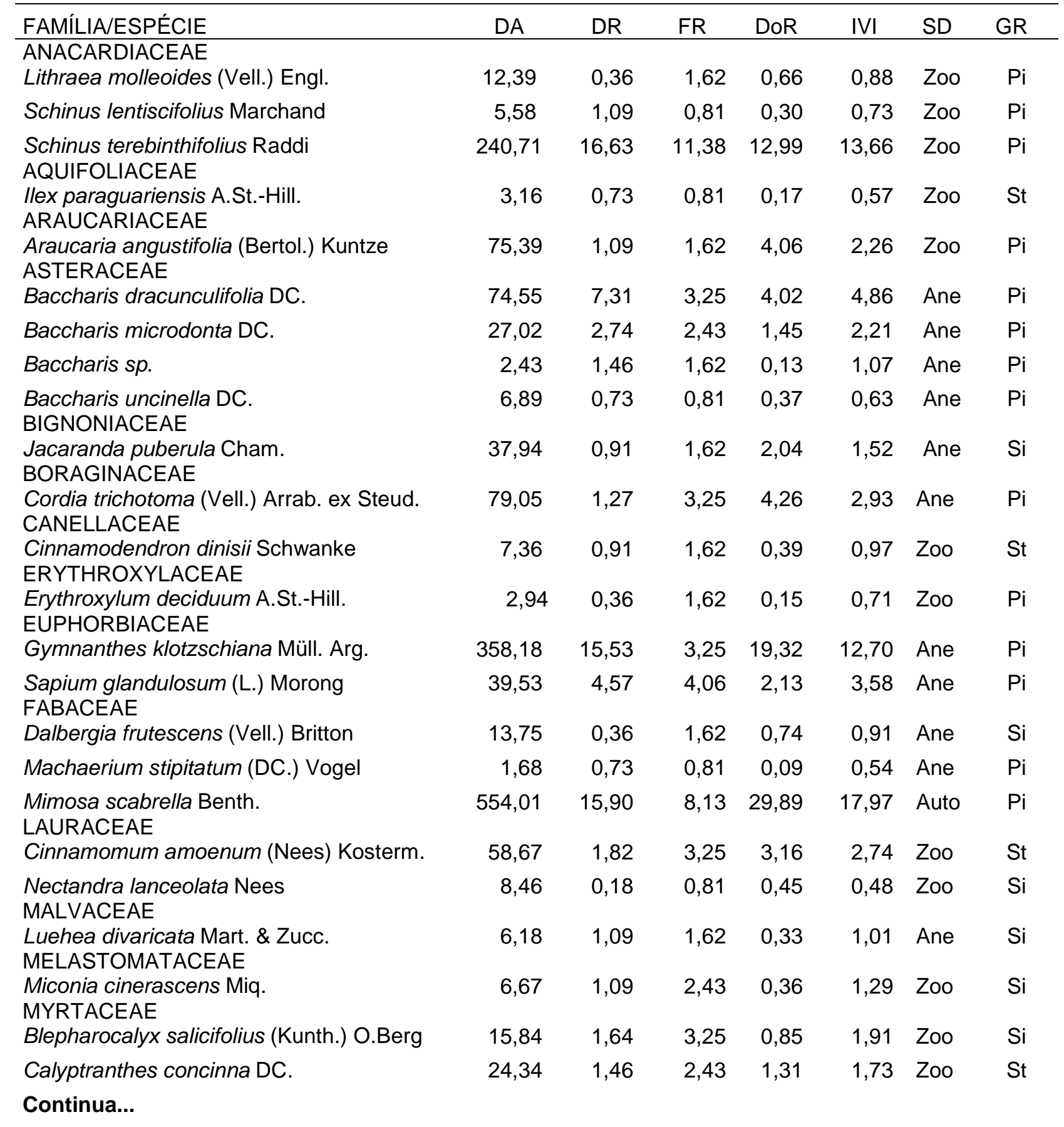




\section{Continuação da tabela $1 \ldots$}

\begin{tabular}{|c|c|c|c|c|c|c|}
\hline Eugenia pluriflora DC. & 34,92 & 4,20 & 2,43 & 1,88 & 2,84 & Zoo \\
\hline Myrceugenia euosma (O.Berg) D. Legrand & 1,07 & 0,18 & 1,62 & 0,05 & 0,62 & Zoo \\
\hline Myrceugenia sp. & 0,43 & 0,36 & 1,62 & 0,02 & 0,67 & Zoo \\
\hline Myrcia laruotteana Cambess. & 1,81 & 0,36 & 1,62 & 0,09 & 0,69 & Zoo \\
\hline Myrcia palustris DC. & 8,71 & 1,64 & 4,06 & 0,47 & 2,06 & Zoo \\
\hline Myrcia splendens (Sw.) DC. & 3,39 & 0,91 & 0,81 & 0,18 & 0,63 & Zoo \\
\hline Myrciaria delicatula (DC.) O.Berg & 5,34 & 0,54 & 0,81 & 0,28 & 0,55 & Zoo \\
\hline $\begin{array}{l}\text { Myrrhinium atropurpureum Schott } \\
\text { PRIMULACEAE }\end{array}$ & 27,39 & 1,09 & 3,25 & 1,47 & 1,94 & Zoo \\
\hline $\begin{array}{l}\text { Myrsine coriacea (Sw.) R. Br. } \\
\text { RUTACEAE }\end{array}$ & 19,03 & 1,46 & 1,62 & 1,02 & 1,37 & Zoo \\
\hline $\begin{array}{l}\text { Zanthoxylum rhoifolium Lam. } \\
\text { SALICACEAE }\end{array}$ & 3,77 & 0,54 & 2,43 & 0,20 & 1,06 & Zoo \\
\hline Casearia decandra Jacq. & 0,73 & 0,54 & 0,81 & 0,03 & 0,46 & Zoo \\
\hline $\begin{array}{l}\text { Xylosma ciliatifolia (Clos) Eichler } \\
\text { SAPINDACEAE } \\
\text { Allophylus edulis (A.St.-Hill., Cambess. \& A }\end{array}$ & 12,22 & 0,73 & 2,43 & 0,65 & 1,27 & Zoo \\
\hline Juss.) Radlk. & 24,51 & 2,92 & 4,06 & 1,32 & 2,77 & Zoo \\
\hline $\begin{array}{l}\text { Matayba elaeagnoides Radlk. } \\
\text { SOLANACEAE }\end{array}$ & 31,23 & 1,46 & 3,25 & 1,68 & 2,13 & Zoo \\
\hline Solanum pabstii L.B.Sm. \& Downs & 0,38 & 0,36 & 0,81 & 0,02 & 0,39 & Zoo \\
\hline $\begin{array}{l}\text { Solanum variabile Mart. } \\
\text { SYMPLOCACEAE }\end{array}$ & 1,67 & 0,91 & 1,62 & 0,09 & 0,87 & Zoo \\
\hline $\begin{array}{l}\text { Symplocos uniflora (Pohl) Benth. } \\
\text { WINTERACEAE }\end{array}$ & 0,87 & 0,54 & 0,81 & 0,04 & 0,46 & Zoo \\
\hline Drimys brasiliensis Miers & 12,62 & 1,09 & 1,62 & 0,68 & 1,13 & Zoo \\
\hline
\end{tabular}

$\mathrm{DA}$ = densidade absoluta; $\mathrm{DR}=$ densidade relativa (em \%); $\mathrm{FR}=$ frequência relativa (em \%); DoR = dominância relativa (em \%); IVI = Índice de valor de importância (em \%); SD = síndrome de dispersão; Ane = Anemocórica; Auto = Autocórica, Zoo =: Zoocórica; GR = Guilda de regeneração; Si = Secundária Inicial; St = Secundária Tardia; $\mathrm{P}=$ Pioneira.

$\mathrm{Na}$ região Sul do Brasil Myrtaceae e Asteraceae tem sido as famílias mais representativas em diversos estudos em mata ciliar (COLONETTI 2009, FERREIRA et al. 2013, TEIXEIRA et al. 2014, RECH et al. 2015, MENDES 2015).

Myrtaceae é considerada uma das famílias mais bem representadas no Brasil, e compreende diversos tipos de vegetação como: Floresta Amazônica (SILVA et al. 2005); Restinga (LOURENÇO \& BARBOSA 2012), Cerrado e, principalmente, na Mata Atlântica (SOBRAL et al. 2009). É uma das famílias mais citadas em estudos florísticos e fitossociológicos. Apresenta grande importância ecológica, pois os frutos das espécies que compõem a família são fontes de alimento à fauna silvestre (GRESSLER et al. 2006) e, por isso, são indicadas para revegetação de áreas perturbadas.

A família Asteraceae predomina nos estratos arbustivos e subarbustivos de formações campestres, sendo também constituída por espécies bastante rústicas e sua elevada riqueza pode ser um indicativo de que a área se apresenta em regeneração pós-distúrbio.

Os gêneros com maior riqueza de espécies foram Baccharis (quatro espécies), Myrcia (três espécies), Schinus (duas espécies), Solanum (duas espécies) e Myrceugenia (duas espécies).

A elevada riqueza de gêneros como Baccharis, indica o caráter inicial do processo de restauração, pois eles apresentam, em geral, espécies que preferem áreas abertas ou florestas alteradas, nas quais existe maior incidência de luz (RECH et al. 2015). Resultados semelhantes foram encontrados por GASPER et al. (2013).

Myrcia é um dos gêneros mais representativos da família Myrtaceae, amplamente distribuído pelo Brasil, apresenta-se em forma de árvores ou arbustos e do ponto de vista florístico ocupa os estratos inferiores da Floresta Ombrófila Mista. A expressiva riqueza de espécies do gênero Myrcia vem sendo comprovada por trabalhos recentes realizados em Floresta Ombrófila Mista Montana e Floresta Ombrófila Densa (HIGUCHI et al. 2012a, LINGNER et al. 2015).

Em relação à estrutura horizontal da floresta, as famílias mais abundantes em número de indivíduos 
foram Euphorbiaceae (110), Anacardiaceae (99), Fabaceae (93), Myrtaceae (68) e Asteraceae (67). Esse conjunto assemelha-se aos de outros estudos da vegetação arbórea realizados nas fitofisionomias de Floresta Ombrófila Mista (HIGUCHI et al. 2012a e 2012b, FERREIRA et al. 2012, RECH et al. 2015, ANSOLIN et al. 2016), área de ecótono entre FOD e FOM (SILVA et al. 2013) e Floresta Ombrófila Densa (COLONETTI et al. 2009).

Os descritores fitossociológicos (Tabela 1) foram calculados a fim de se verificar a participação de cada espécie na comunidade. Dentre as espécies, Mimosa scabrella foi a que mais se destacou, com valor de importância relativo (IVI) de aproximadamente $6 \%$. Schinus terebinthifolius foi a espécie de maior densidade na área estudada ( $D R=16,6 \%$ ), o que contribuiu para que esta tivesse o segundo maior IVI (4,5\%). Com o terceiro maior IVI (4,2\%) está Gymnanthes klotzschiana (Figura 1).

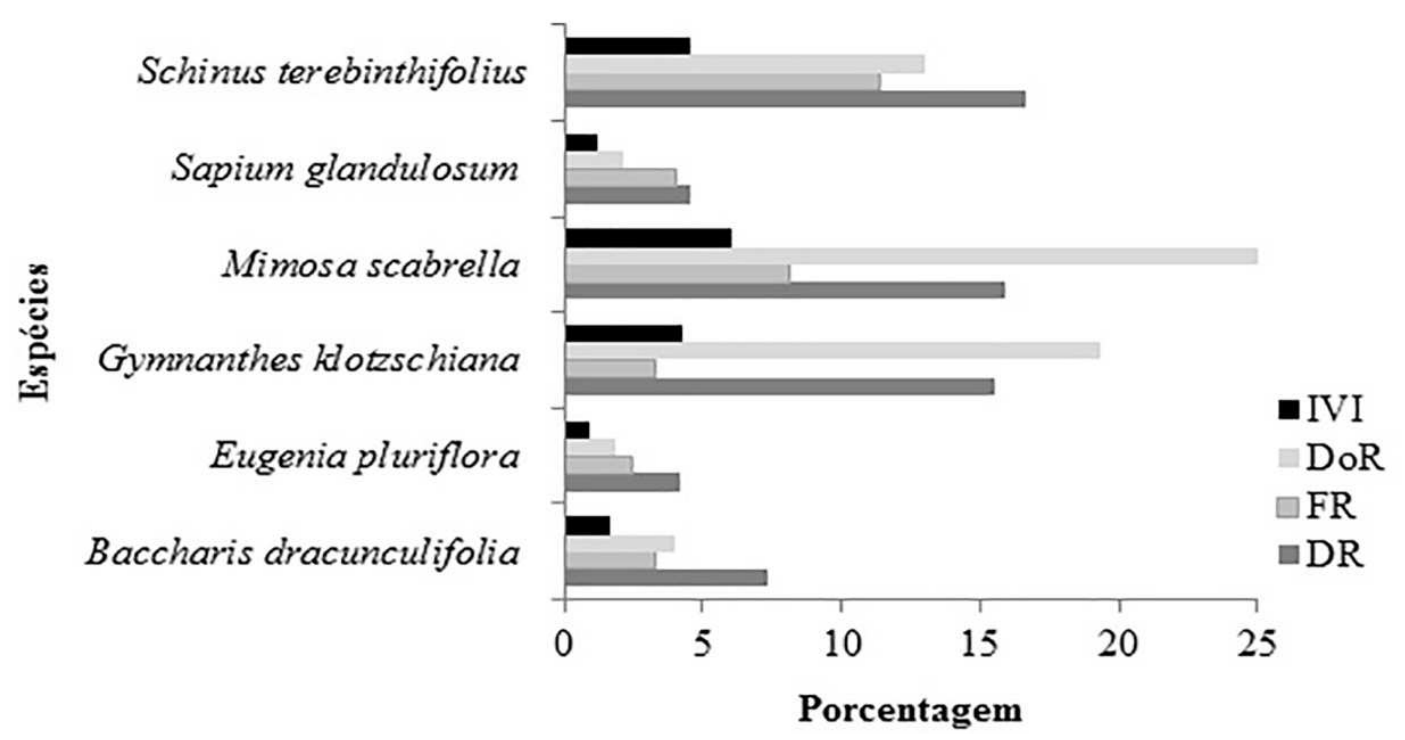

Figura 1. Parâmetros da estrutura horizontal, frequência relativa (FR), dominância relativa (DoR), densidade relativa (DR) e índice de valor de importância relativo (IVI) das espécies mais importantes.

Figure 1. Parameters of the horizontal structure, relative frequency $(F R)$, relative dominance $(D o R)$, relative density (DR), relative importance value index (IVI) of the most important species.

As espécies com os maiores valores de importância se destacaram devido às suas elevadas abundâncias de indivíduos, ocorrência na maioria das parcelas e altos valores de dominâncias, sendo também as espécies com maior potencial para a recuperação de áreas degradadas entre as espécies encontradas.

M. scabrella é uma espécie pioneira de rápido crescimento e recobrimento do solo, apresenta interações com micro-organismos do solo, contribui com elevada produção de biomassa foliar incrementando a ciclagem de nutrientes favorecendo o desenvolvimento dos processos ecológicos envolvidos na sucessão florestal. Além disso, é comumente encontrada em maior densidade no banco de sementes do solo, devido à grande produção, eficiente dispersão e dormência das sementes, sendo encontrada em áreas que sofreram perturbações e ocupa os estágios iniciais na FOM.

Schinus terebinthifolius possui alta plasticidade de colonização, estabelecendo-se em solos úmidos, secos e arenosos a argilosos (LENZI \& ORTH 2004). É amplamente disseminada por pássaros e devido a características como agressividade competitiva, tolerância higromórfica, boa interação biótica, caráter pioneiro, apresenta forte potencial de regeneração em ambientes antropizados (KAGEYAMA \& GANDARA 2000).

Gymnanthes klotzschiana conhecida como branquilho, característica do estrato arbóreo de florestas ciliares (CARVALHO 2003), devido ao seu valor ecológico é indicada para recuperação de áreas degradadas. De acordo com KLEIN (1966), Gymnanthes klotzschiana é uma das espécies pioneiras mais expressivas. Estudo conduzido em área de preservação permanente por FERREIRA et al. (2013), também obtiveram Gymnanthes klotzschiana como a espécie com elevado valor de importância.

A maior proporção de pioneiras, por sua vez, demonstra que aos poucos a vegetação será substituída pelas espécies secundárias iniciais e tardias. As espécies secundárias apresentam crescimento lento, menores produção de sementes e desenvolvem-se preferencialmente à sombra em comunidades de maior diversidade de espécies e menor densidade populacional (GONÇALVES et al. 2003). 
As espécies consideradas raras, com apenas um indivíduo registrado, foram Myrceugenia euosma e Nectandra lanceolata. O conceito de espécies raras considera aquelas representadas por apenas um indivíduo na amostra. Isso mostra que a abundância de uma espécie pode variar de um local para o outro, devido à plasticidade, preferência por outras regiões fitoecológicas, altitude, características do solo, topografia, drenagem e entre outros fatores. Em estudo da composição florística da floresta ciliar do rio Pelotas MENDES (2015), obteve Myrceugenia euosma como espécie rara de FOM. FERREIRA et al. (2015), obtiveram Nectandra lanceolata como espécie rara com distribuição restrita na área estudada.

O valor do índice de diversidade de Shannon-Wiener $\left(\mathrm{H}^{\prime}\right)$ obtido para o presente estudo foi de 2,9 e a Equabilidade de Pielou (J') foi de 0,78. O Índice de Shannon é um dos índices mais frequentemente utilizados para avaliar a diversidade e expressa a uniformidade dos valores de importância por meio de todas as espécies da parcela. É afetado por espécies raras, ou seja, o índice valoriza estas (KANIESKI et al. 2010). De acordo com DURIGAN (1999), os valores deste índice em geral situam-se entre 1,50 e 3,50 para Floresta Ombrófila Mista. $O$ índice de Shannon apresentou valores que indicaram uma baixa diversidade de espécies quando comparados a outros estudos em APP em FOM, como o realizado por FIORENTIN et al. (2015), que obtiveram $H^{\prime}=3,13$ em uma APP de FOM e o de SILVA et al. (2012), que encontraram $H^{\prime}=3,6$ em um fragmento de FOM.

Valor de diversidade semelhante ao do presente estudo foi obtido por RECH et al. (2015), que encontraram H'=2,91 em área de transição FOD - FOM. ARAUJO et al. (2016), comparando a diversidade florística da regeneração natural de uma mata ciliar em Floresta Ombrófila Mista, encontrou um valor de $H^{\prime}=2,55$, inferior ao do presente estudo, indicando que a área analisada neste estudo possui maior diversidade florística. $O$ valor encontrado expressa o grau de alteração e perturbação da área e pode servir como referência para outras áreas com características semelhantes.

O Índice de Pielou é um índice de equidade que mede a proporção da diversidade observada em relação à máxima diversidade esperada. Os valores nesse índice podem ocorrer de $0 \mathrm{a} 1$, sendo que quanto mais próximo de 1, maior a uniformidade do local (KANIESKI et al. 2010). O valor encontrado para este índice denotou de média a alta uniformidade na distribuição dos indivíduos por espécie, com o predomínio de algumas poucas espécies com um número maior de indivíduos. Valores semelhantes também foram relatados por FIORENTIN et al. (2015) com valor de 0,77 e RECH et al. (2015) com valor de 0,78 para o índice de Pielou.

Em relação à síndrome de dispersão (Tabela 1), a maioria das espécies apresentaram características zoocóricas, seguidas pelas anemocóricas e autocóricas (Figura 2A). Quanto à Guilda de regeneração (Tabela 1), se observa que a quantidade de espécies com características de pioneiras foram superiores às secundárias iniciais e secundárias tardias (Figura 2B).

A

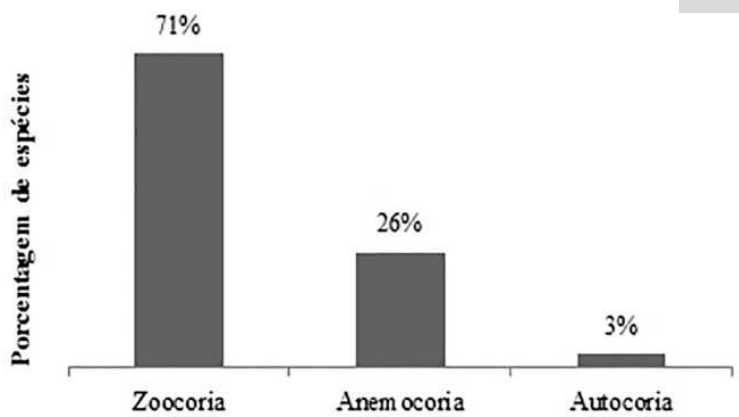

Sindrome de dispersão
B

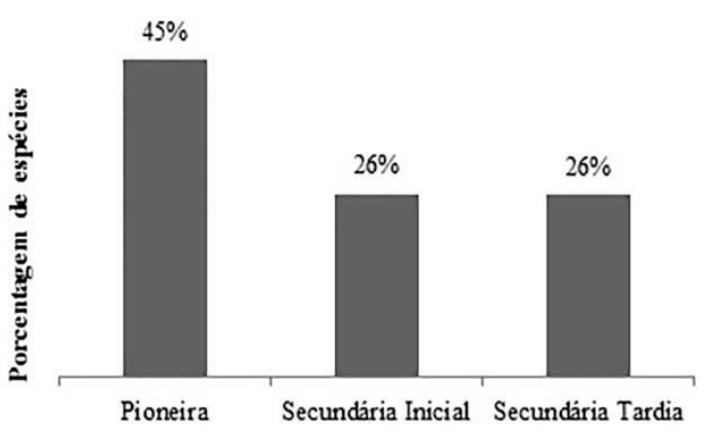

Guilda de regeneração

Figura 2. A) Síndrome de dispersão e B) Guilda de regeneração de espécies encontradas em levantamento florístico em área de preservação permanente do rio Canoas no município de Otacílio Costa, SC.

Figure 2. A) Dispersion syndrome and B) Guild of regeneration of species found in floristic survey in a permanent preservation area of Canoas river in the municipality of Otacilio Costa, SC.

A porcentagem de espécies zoocóricas encontradas neste estudo, demostra a importância da relação entre fauna e flora no fluxo gênico em formações florestais. De acordo com DEMINICIS et al. (2009), a fauna ao dispersar sementes e propágulos, contribui para a regeneração natural da área, permitindo que esta recupere sua resiliência e se torne autossustentável novamente. BUDKE et al. (2005), descreveram 
que, em uma floresta estacional ribeirinha, a estratégia de dispersão também mais encontrada foi a zoocórica (72\%), seguida anemocórica (24\%) e autocórica (4\%). MENDES (2015) obteve 82\% das espécies zoocóricas, $13 \%$ anemocóricas e $5 \%$ autocóricas. Isso significa que a área de estudo apresenta uma riqueza importante de espécies atrativas à fauna dispersora, em que as interações planta-animal podem ser simples ou mais complexas, como por exemplo, locais para a nidificação, empoleiramento, forrageamento, herbívora, polinização e proteção contra predadores.

Em relação à guilda de regeneração foram encontradas $45 \%$ de espécies pioneiras, $26 \%$ secundárias iniciais e $26 \%$ secundárias tardias. ARAUJO et al. (2010) encontraram em um remanescente de FOM, $18 \%$ de espécies pioneiras, o que caracteriza uma floresta mais madura, diferente do presente estudo, caracterizado por processo de sucessão secundária inicial.

Espécies características de processo inicial de sucessão possuem ótimo potencial para a recuperação de áreas degradadas, principalmente com características de áreas abertas, com forte exposição solar, em que as espécies pioneiras poderão ocupar mais rapidamente o local degradado e propiciar melhores condições para que espécies de estágios sucessionais mais avançados ocupem o local, permitindo a evolução da sucessão florestal. Grande parte das espécies encontradas no levantamento possui essa característica, sendo consideradas com ótimo potencial para ocupação de áreas degradadas em fitofisionomia semelhante, principalmente as espécies Mimosa scabrella, Schinus terebinthifolius e Gymnanthes klotzschiana, que também apresentaram os maiores valores de importância.

\section{CONCLUSÃO}

A área de preservação permanente estudada apresentou uma riqueza específica representada pelas famílias Myrtaceae e Asteraceae, com predominância de espécies dos gêneros Baccharis, Myrcia, Schinus, Solanum e Myrceugenia.

A maioria das espécies identificadas pertence à guilda de regeneração das pioneiras, indicando que a área de estudo se encontra em estágio inicial de sucessão. Houve predomínio de espécies zoocóricas, o que tem grande importância, pois a entrada de propágulos está ligada diretamente à fauna e caracteriza diversas espécies com potencial para recuperação.

Mimosa scabrella, Schinus terebinthifolius e Gymnanthes klotzschiana apresentaram os maiores valores de importância, além de serem consideradas as principais espécies com potencial para uso em planos de restauração florestal em áreas de preservação permanente degradadas na região.

Os resultados observados mostraram que a área de preservação permanente sofreu perturbações no passado, o que reflete na qualidade do fragmento, contudo se encontra em estágio de recuperação e apresenta espécies com forte potencial de recuperação que podem servir de base para uso em áreas com características semelhantes.

\section{REFERÊNCIAS}

ALARCON GG et al. 2011. Fragmentação da Floresta com Araucária e ecossistemas associados no Corredor Ecológico Chapecó, Santa Catarina. Biotemas 24: 25-38.

ALMEIDA DS. 2016. Recuperação ambiental da Mata Atlântica. 3.ed. llhéus: Editus.

ALVARES CA et al. 2014. Köppen's climate classification map for Brazil. Meteorologische Zeitschrift 22: 711-718.

ANSOLIN RD et al. 2016. Heterogeneidade ambiental e variação florístico-estrutural em um fragmento de Floresta com Araucária na Coxilha Rica - SC. Ciência Florestal 26: 1201-1210.

APG. 2009. Angiosperm Phylogeny Group - III. An update of the Angiosperm Phylogeny Group classification for the orders and families of flowering plants. Botanical Journal of the Linnean Society 161: 105-121.

ARAUJO ACB et al. 2016. Estrutura de dois componentes arbóreos de Floresta Subtropical Ripária na Campanha Gaúcha, Sant'ana do Livramento, RS. Floresta 46: 481-490.

ARAUJO MM et al. 2010. Análise de agrupamento em remanescente de Floresta Ombrófila Mista. Ciência Florestal 20: $1-18$.

BRASIL. 2012. Lei o 12.651 de 2012. Dispõe sobre a proteção da vegetação nativa. Brasília. Disponível em: http://www.planalto.gov.br/ccivil_03/_ato2011-2014/2012/lei/12651.htm. Acesso em: 18 set. 2017.

BUDKE JC et al. 2005. Composição florística e estratégias de dispersão de espécies lenhosas em uma floresta ribeirinha, arroio Passo das Tropas, Santa Maria, RS, Brasil. Iheringia 60: 17-24.

CARVALHO PER. 2003. Espécies arbóreas brasileiras. Brasília: EMBRAPA Informação Tecnológica.

COLONETTI S et al. 2009. Florística e estrutura fitossociológica em Floresta Ombrófila Densa Submontana na barragem do rio São Bento, Siderópolis, Estado de Santa Catarina. Acta Scientiarum. Biological Sciences 31: 397405.

DEMINICIS BB et al. 2009. Dispersão natural de sementes: importância, classificação e sua dinâmica nas pastagens tropicais. Archivos de Zootecnia 50: 35-58. 
DURIGAN ME. 1999. Florística, dinâmica e análise protéica de uma Floresta Ombrófila Mista em São João do Triunfo PR. Dissertação (Mestrado em Engenharia Florestal). Curitiba: UFPR. 125p.

EMBRAPA. 2013. Empresa Brasileira de Pesquisa Agropecuária. Sistema Brasileiro de Classificação de Solos. 3.ed. Brasília: EMBRAPA. 353p.

EPAGRI. 2002. Empresa de Pesquisa Agropecuária e Extensão Rural de Santa Catarina. Dados e Informações Biofísicas da Unidade de Planejamento Regional Planalto Sul Catarinense. Florianópolis: UPR. 76p.

FERREIRA PI et al. 2012. Florística e fitossociologia arbórea de remanescentes florestais em uma fazenda produtora de Pinus spp. Floresta 42: 783-794.

FERREIRA PI et al. 2013. Espécies Potenciais para Recuperação de Áreas de Preservação Permanente no Planalto Catarinense. Floresta e Ambiente 20: 173-182.

FERREIRA TS et al. 2015. Formas de raridade de árvores em fragmentos de Floresta Ombrófila Mista no sul do Brasil. Scientia Forestalis 43: 931-941.

FIORENTIN LD et al. 2015. Análise florística e padrão espacial da regeneração natural em área de Floresta Ombrófila Mista na região de Caçador, SC. Floresta e Ambiente 22: 60-70.

FUNDAÇÃO SOS MATA ATLÂNTICA \& INPE. 1998. Atlas da evolução dos remanescentes florestais e ecossistemas associados do domínio da Mata Atlântica no período 1990-1995. São Paulo: Fundação SOS Mata Atlântica. 29p.

GANDOLFI S et al. 1995. Levantamento florístico e caráter sucessional das espécies arbustivo-arbóreas de uma floresta mesófila semidecídua no município de Guarulhos, SP. Revista Brasileira de Botânica 55: 753-767.

GASPER AL et al. 2013. Inventário florístico florestal de Santa Catarina: espécies da Floresta Ombrófila Mista. Rodriguésia 64: 201-210.

GONÇALVES JLM et al. 2003. Recuperação de solos degradados. In: KAGEYAMA PY et al. (Orgs.). Restauração ecológica de ecossistemas naturais. Botucatu: FEPAF. p.51-76.

GRESSLER E et al. 2006. Polinização e dispersão de sementes em Myrtaceae do Brasil. Revista Brasileira de Botânica 29: $509-530$.

GUERRA MP et. al. 2002. Exploração, manejo e conservação da araucária (Araucaria angustifolia). In: SIMÕES LL. LINO CF. (Ed.). Sustentável Mata Atlântica: a exploração de seus recursos florestais. São Paulo: SENAC. p.85-102.

HIGUCHI P et al. 2012a. Influência de variáveis ambientais sobre o padrão estrutural e florístico do componente arbóreo, em um fragmento de Floresta Ombrófila Mista Montana em Lages, SC. Ciência Florestal 22: 79-90.

HIGUCHI P et al. 2012b. Floristic composition and phytogeography of the tree component of Araucaria Forest fragments in southern Brazil. Brazilian Journal of Botany 35: 145-157.

IBGE. 2012. Instituto Brasileiro de Geografia e Estatística. Manual Técnico da Vegetação Brasileira. 2.ed. Rio de Janeiro: Fundação Instituto. 275p.

HOLDRIDGE LR et al. 1971. Forest environment in tropical life zones: a pilot study. Pergamon Press. 747p.

KAGEYAMA P \& GANDARA FB. 2000. Revegetação de áreas ciliares. In: RODRIGUES RR \& LEITÃO-FILHO HF (Eds.). Matas ciliares: conservação e recuperação. São Paulo: EDUSP. p.235-247.

KANIESKI MR et al. 2010. Quantificação da diversidade em Floresta Ombrófila Mista por meio de diferentes índices alfa. Scientia Forestalis 38: 567-577.

KLEIN RM. 1966. Árvores nativas indicadas para o reflorestamento no Sul do Brasil. Selowia 18: 29-29.

LENZI M \& ORTH AF. 2004. Fenologia reprodutiva, morfologia e biologia floral de Schinus terebinthifolius Raddi (Anacardiaceae), em restinga da llha de Santa Catarina, Brasil. Biotemas 17: 67-89.

LINGNER DV et al. 2015. Floresta Ombrófila Densa de Santa Catarina - Brasil: agrupamento e ordenação baseados em amostragem sistemática. Ciência Florestal 25: 933-946.

LFB - LISTA DE ESPÉCIES DA FLORA DO BRASIL. 2016. Jardim Botânico do Rio de Janeiro. Disponível em: http://floradobrasil.jbrj.gov.br/. Acesso em: 12 set. 2016.

LOURENÇO ARL \& BARBOSA MRV. 2012. Myrtaceae em restingas no limite norte de distribuição de Mata Atlântica, Brasil. Rodriguésia 63: 373-393.

MARTINS FR. 1993. Estrutura de uma floresta mesófila. 2.ed. Campinas: UNICAMP. 246p.

MARQUESINI NR. 1995. Plantas usadas como medicinais pelos índios do Paraná e Santa Catarina, Sul do Brasil: guarani, kaingang, xokleng, ava-guarani, kraô e cayuá. Dissertação (Mestrado em Botânica). Curitiba: UFPR. 361p.

MENDES AR. 2015. Floresta ciliar do rio pelotas ao longo de um gradiente altitudinal: fitossociologia e variáveis edáficas. Dissertação (Mestrado em Engenharia Florestal). Lages: UDESC. 113p.

NEGRINI M et al. 2012. Dispersão, distribuição espacial e estratificação vertical da comunidade arbórea em um fragmento florestal no Planalto Catarinense. Revista Árvore 36: 919-929.

NERI AV et al. 2011. Espécies de Cerrado com potencial para recuperação de áreas degradadas por mineração de ouro, Paracatu-MG. Revista Árvore 35: 907-918.

RECH CCC et al. 2015. Avaliação da restauração florestal de uma APP degradada em Santa Catarina. Floresta e Ambiente 22: 194-203.

RODE R et al. 2011. Grupos florísticos e espécies discriminantes em povoamento de Araucaria angustifolia e uma Floresta Ombrófila Mista. Revista Árvore 35: 319-327.

SILVA AC et al. 2012. Relações florísticas e fitossociologia de uma Floresta Ombrófila Mista Montana secundária em Lages, Santa Catarina. Ciência Florestal 22: 193-206.

SILVA AC et al. 2013. Caracterização fitossociológica e fitogeográfica de um trecho de floresta ciliar em Alfredo Wagner, SC, como subsídio para restauração ecológica. Ciência Florestal 23: 579-593. 
SILVA JMC et al. 2005. Destino das áreas de endemismo da Amazônia. Megadiversidade 1: 124-131.

SOBRAL M et al. 2009. Myrtaceae. In: STHEMAN J et al. Plantas da Floresta Atlântica. Rio de Janeiro: Instituto de Pesquisas Jardim Botânico do Rio de Janeiro. 516p.

TEIXEIRA M et al. 2014. Estrutura da comunidade arbórea de um fragmento de Mata Ciliar do rio Taquari, Colinas, Rio Grande do Sul. Revista Jovens Pesquisadores 4: 19-31.

TRES DR \& REIS A. 2007. La nucleación como propuesta para la restauración de la conectividad del paisaje. In: II Seminário Internacional de Restauración Ecológica. Santa Clara: Grupo Cubano de Restauración Ecológica. p.32-42. VAN DER PIJL L. 1982. Principles of dispersal in higher plants. 3.ed. Berlin: Springer Verlag. 162p. 